\title{
Lithium tri-sec-butylborodeuteride: a new reagent for the stereoselective deuterium addition to cyclohexanones with single chair conformations
}

\author{
Peter Gärtner, ${ }^{\mathrm{a}}$ Clemens Novak, ${ }^{\mathrm{a}}$ Max Knollmüller, ${ }^{\mathrm{a}}$ and Günther Gmeiner, \\ ${ }^{a}$ Institute of Organic Chemistry, Vienna University of Technology, \\ Getreidemarkt 9, A-1060 Vienna, Austria, Fax: +43-1-58801-154 92. \\ ${ }^{b}$ Österreichisches Forschungszentrum Seibersdorf Ges.m.b.H., A - 2444 Seibersdorf, Austria \\ E-mail: pgaertne@mail.zserv.tuwien.ac.at
}

Dedicated to Professor Fritz Sauter on the occasion of his $70^{\text {th }}$ birthday

(received 29 Dec 00; accepted 28 Oct 01; published on the web 05 Nov 01)

\begin{abstract}
The preparation and application of a new reagent for stereoselective deuterium addition to substituted cyclohexanones is described affording cyclohexanols with axial hydroxy group with high stereoselectivity. The results are compared with other established reduction methods.
\end{abstract}

Keywords: Deuteride addition, alcohols, diastereoselective reduction, stereoselective synthesis, cyclo-hexanones, cyclohexanols, steroids

\section{Introduction}

Deuterated steroids like 2,2,3,4,4- $d_{5}$-androsterone $\mathbf{A}$ and its conjugates may play an important role as internal standards ${ }^{1}$ for the qualitative and quantitative analysis of banned substances used for efficiency enhancement in high-performance sports. The configuration at 3-C of these 3hydroxy-substituted steroids is considered to be decisive: Usually, the compounds to be analyzed have a defined configuration of the 3-hydroxy group, and in order to avoid any difference in the reactivity between a substance used as reference standard and a substrate to be analyzed, the configurations of both should be the same.

A prerequisite for the utilization of a compound as a reference sample in dope analysis is the facile synthesis with high overall yield. One of the key steps in this procedure is the stereoselective reduction of a carbonyl group in position 3 with deuteride reagents. For substrates with a single chair conformation the stereochemistry of hydride addition can be anticipated just by selecting the appropriate reducing agent. ${ }^{2}$ Thus, sterically demanding reagents like Selectride ${ }^{\circledR}$ [e.g. Li(sec-butyl) ${ }_{3} \mathrm{BH}$ ] convert carbonyl groups into alcohols with axial hydroxy groups, whereas sterically less demanding hydride reagents like $\mathrm{LiAlH}_{4}$ yield predominately alcohols with an equatorial hydroxy group. So far, the addition of deuteride to carbonyl groups has been 
performed only with a limited number of commercially available reagents, i.e. $\mathrm{LiAlD}_{4}$ or $\mathrm{NaBD}_{4}$. Both reagents attack from the axial direction furnishing the $3 \beta$-deuterio-3 $\alpha$-hydroxy derivative ( $3 \beta-d-\mathbf{A}$; Figure 1). Thus, the usually applied protocol for the preparation of $3 \alpha$-deuterio-3 $\beta$ hydroxy derivatives $(3 \alpha-d-\mathbf{A})$ requires the subsequent inversion of the alcohol functionality of $3 \beta-d-\mathbf{A}$ by one of the standard procedures, 3 preferably under Mitsunobu conditions, ${ }^{3 b-c}$ necessitating at least one additional linear synthesis step. This situation prompted us to design a sterically congested deuteride reagent providing direct access to axial alcohols.

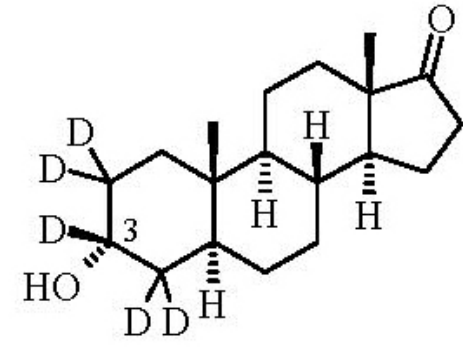

A

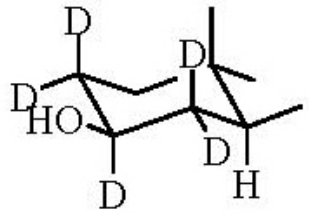

$3 \beta-d-\mathbf{A}$

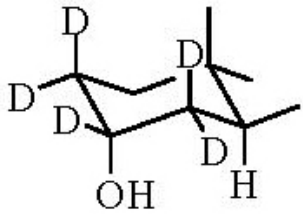

$3 \alpha-d-\mathbf{A}$

\section{Figure 1}

This paper reports on the preparation of such a new reagent and on some first results obtained from the reduction of substituted cyclohexanones 1a-e. Furthermore, the selectivities achieved were compared with those obtained with other established methods.

\section{Results and Discussion}

\section{Preparation of deuteride reagents}

Our first goal was to obtain lithium tri-sec-butyl-borodeuteride which would fulfill the criteria of a sterically congested deuteride reagent. The easiest way ${ }^{4}$ to achieve this was by quenching a lithium aluminum deuteride solution with three equivalents of methanol and treating the obtained lithium trimethoxyaluminum deuteride solution $\left[\mathrm{Li}\left(\mathrm{CH}_{3} \mathrm{O}\right)_{3} \mathrm{AlD}\right]$ with one equivalent of tri-secbutylborane to afford lithium tri-sec-butylborodeuteride which is the deuterium analogue of LSelectride ${ }^{\circledR .4}$ The reagent produced by this method always contains $\mathrm{Al}\left(\mathrm{OCH}_{3}\right)_{3}$ which is difficult to separate. Fortunately, the aluminum salt does not appear to interfere with the use of the lithium tri-sec-butylborodeuteride as it was also described for L-Selectride ${ }^{\circledR .4}$

An alternative procedure ${ }^{5}$ which has been described to give a solution of L-Selectride ${ }^{\circledR}$ without any impurity ${ }^{5}$ is the direct conversion of lithium aluminum deuteride with tri-secbutylborane in the presence of triethylenediamine (TED). In this preparation, TED precipitates $\mathrm{AlD}_{3}$ which is the by-product from the reaction of lithium aluminum deuteride and tri-secbutylborane beside the desired lithium tri-sec-butylborodeuteride. The precipitated TED $\cdot \mathrm{AlD}_{3}$ 
complex can be easily separated by centrifugation. In our hands however, using a reagent solution prepared by this method, the reduction of 4-phenylcyclohexanone to 4phenylcyclohexanol resulted in a poorer diastereoselectivity than that obtained with the reagent synthesized via lithium trimethoxyaluminum deuteride.

A reason for this reduced diastereoselectivity could be the solvent employed: Our experiments were carried out in THF because most reagents were supplied as THF solutions, whereas the literature procedure ${ }^{5}$ used diethyl ether. This influence of the solvent was unexpected because it has been described ${ }^{6}$ that alane $\left(\mathrm{AlH}_{3}\right)$ can be precipitated quantitatively with TED in THF as well as in diethyl ether; thus, the obtained solution of lithium tri-secbutylborodeuteride should be of comparable quality.

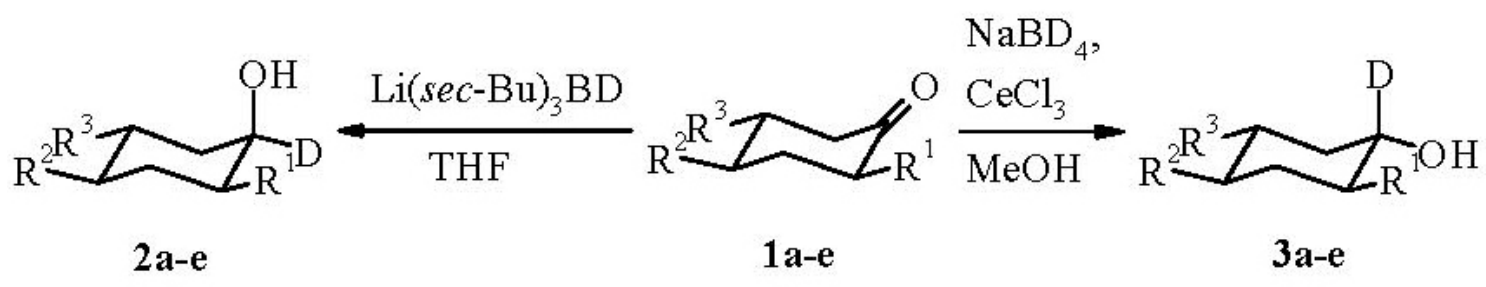

\begin{tabular}{c|ccc} 
1, 2, 3 & $\mathrm{R}^{1}$ & $\mathrm{R}^{2}$ & $\mathrm{R}^{3}$ \\
\hline $\mathbf{a}$ & $\mathrm{H}$ & $\mathrm{C}_{6} \mathrm{H}_{5}$ & $\mathrm{H}$ \\
$\mathbf{b}$ & $\mathrm{H}$ & $\mathrm{C}^{\left(\mathrm{CH}_{3}\right)_{3}}$ & $\mathrm{H}$ \\
$\mathbf{c}$ & $\mathrm{H}$ & $\mathrm{CH}_{3}$ & $\mathrm{H}$ \\
$\mathbf{d}$ & $\mathrm{CH}_{3}$ & $\mathrm{H}$ & $\mathrm{H}$ \\
e & $\mathrm{CH}\left(\mathrm{CH}_{3}\right)_{2}$ & $\mathrm{H}$ & $\mathrm{CH}_{3}$
\end{tabular}

\section{Scheme 1}

\section{Refinement of the protocol for the synthesis of the lithium tri-sec-butylborodeuteride solution. Determination of the concentration of the LiAlD $_{4}$ solution}

The lithium tri-sec-butylborodeuteride solution obtained via lithium trimethoxy-aluminum deuteride performed well, as long as some crucial parameters in the preparation of the reagent were carefully observed. In order to achieve good selectivities in the reduction of cyclohexanones it is essential to know precisely the concentration of the lithium aluminum deuteride solution employed for the preparation of a lithium tri-sec-butylborodeuteride solution because the concentration of the former solution varies significantly with age. In principle, the concentration of the lithium aluminum deuteride solution can be provided by gas-volumetric determination of hydrogen evolved by hydrolysis, but unexpectedly, sometimes we obtained too high values for active deuteride as judged from subsequent reduction experiments. This became evident from the following observation: when three equivalents of methanol were added according to the concentration $(1.15 \mathrm{M})$ determined by the gas-volumetric method, we got no 
reductive addition of deuteride at all, even when three equivalents of the reagent were used. This can be explained only by the fact that all deuteride equivalents present in the starting lithium aluminum deuteride solution have been already consumed by methanol. This means that too much methanol has been added, and this results leads to the conclusion that the concentration of deuteride as determined by a gas-volumetric method on which the calculation of three equivalents of methanol was based on must have been too high.

Table 1. Determination of the active deuteride concentration of an in situ prepared lithium trisec-butylborodeuteride solution from a LiAlD4 solution (ca. $1 \mathrm{M}, 0.89 \mathrm{~mL}$ )

\begin{tabular}{cccclcl}
\hline Exp. & $\begin{array}{c}\text { Ketone 1d } \\
{[\mathrm{mmol}]}\end{array}$ & $\begin{array}{c}\mathrm{MeOH} \\
{[\mathrm{mmol}]}\end{array}$ & $\begin{array}{c}(\mathrm{sec}-\mathrm{Bu})_{3} \mathrm{~B} \\
{[\mathrm{mmol}]}\end{array}$ & Conversion & $\begin{array}{c}\text { Product ratio* } \\
\text { 2d:3d }\end{array}$ & $\begin{array}{l}\mathrm{LiAlD}_{4} \\
{[\mathrm{mmol} / \mathrm{mL}]^{\#}}\end{array}$ \\
\hline 1 & 0.30 & 3.07 & 1.13 no & & - & $<0.86$ \\
2 & 0.30 & 2.67 & 0.98 & partial & $89: 11$ & $>0.75 ;<1.00$ \\
3 & 0.30 & 2.45 & 0.98 & nearly complete & $97: 3$ & $>0.69 ;<0.92$ \\
4 & 0.30 & 2.38 & 0.98 & complete & $96: 4$ & $>0.67 ;<0.89$ \\
5 & 0.76 & 2.38 & 0.98 & complete not & detmined & $\sim 0.88$ \\
\hline
\end{tabular}

* The ratio 2d:3d was determined by GC analysis. All ratios given in the following tables are also based on this analytical method.

\# The limit concentration was calculated with the following formulae:

$\mathrm{LiAlD}_{4}[\mathrm{mmol} / \mathrm{mL}]=\left(\mathrm{MeOH}[\mathrm{mmol}]+\mathbf{1 d}_{\text {reduced }}[\mathrm{mmol}]\right) /(4$ x $0.89[\mathrm{~mL}])$;

if no reduction takes place: $\mathrm{LiAlD}_{4}[\mathrm{mmol} / \mathrm{ml}]<(\mathrm{MeOH}[\mathrm{mmol}] /(4 \times 0.89[\mathrm{~mL}])$, because in this case no deuteride is present after the addition of $\mathrm{MeOH}$;

for complete or partial reduction of $\mathbf{1 d}$ :

$\mathrm{LiAlD}_{4}[\mathrm{mmol} / \mathrm{ml}]>(\mathrm{MeOH}[\mathrm{mmol}]) /(4 \times 0.89[\mathrm{~mL}])$, because otherwise no reduction would be observed;

and $\mathrm{LiAlD}_{4}[\mathrm{mmol} / \mathrm{mL}]<(\mathrm{MeOH}[\mathrm{mmol}]) /(3 \times 0.89[\mathrm{~mL}])$, because otherwise the selectivity 2d:3d would drop significantly.

Therefore, we tried to get the appropriate concentration by an empirical approach. Since the lithium tri-sec-butylborodeuteride solution which was prepared from $0.89 \mathrm{~mL}$ of $\mathrm{LiAlD}_{4} \mathrm{solution}$ and $3.07 \mathrm{mmol}$ of methanol and $1.13 \mathrm{mmol}$ of tri-sec-butylborane did not reduce any ketone (Table 1, exp. 1) we prepared another reagent solution with less methanol and tri-secbutylborane added to the lithium aluminum deuteride solution (Table 1, exp. 2). We always used a slight excess of tri-sec-butylborane (1.1 equiv.) to ensure that all deuteride was bound to boron. However, as can be seen from experiment 2, the relative ratio of $\mathrm{MeOH}$ :tri-sec-butylborane (3:1.1) turned out to be too low (because the observed selectivity was only 89:11), and a large portion of the starting material remained unchanged; this again must be due to too much $\mathrm{MeOH}$ being added to the $\mathrm{LiAlD}_{4}$ solution. Thus, in experiment 3 we further reduced the amount of methanol, the relative ratio of $\mathrm{MeOH}$ :tri-sec-butylborane was increased from 3:1.1 to 3:1.2 
equiv. (Table 1, exp. 3). Now the stereoselectivity was quite good, and the conversion was nearly complete. However, this result was still not optimal, and therefore, we carried out another experiment with the amount of methanol even further reduced while the amount of tri-secbutylborane was kept unchanged (Table 1, exp. 4). This resulted in complete conversion, and the selectivity was as high as before. To check whether the observed results are consistent we calculated a rough value for the concentration of the $\mathrm{LiAlD}_{4}$ solution based on two assumptions: More than 4 equivalents of methanol yielded no reduction product, less than 3 equivalents gave poorer stereoselectivity (for details on this calculation see footnote in Table 1). Based on the results of these calculations, the concentration of methanol must be between $0.75 \mathrm{mmol} / \mathrm{mL}$ (Table 1, exp. 2) and $0.86 \mathrm{mmol} / \mathrm{mL}$ (Table 1, exp. 1).

Eventually, a definite value of the favorable concentration of the $\mathrm{LiAlD}_{4}$ solution was determined: We prepared a reducing agent solution and added ketone 1d until the ketone was not consumed any more as monitored by TLC (Table 1, exp. 5). The concentration of the $\mathrm{LiAlD}_{4}$ solution determined by this method was $0.88 \mathrm{mmol} / \mathrm{mL}$ and fitted nearly perfectly with all other data. All further experiments in this paper are based on this concentration of the $\mathrm{LiAlD}_{4}$ solution. However, bearing in mind that in order to optimize the stereoselectivity of the ketone reduction an excess of methanol is favorable, in some instances, owing to the small scale of the reactions, the relative amount of methanol and tri-sec-butylborane was somewhat higher (ca. 5\%) than the amount which would have been required based on the concentration of the $\mathrm{LiAlD}_{4}$ solution $(0.88 \mathrm{mmol} / \mathrm{mL})$. It should be noted that the reagent prepared in the described manner deteriorated upon storage. A reagent solution that was kept in a sealed flask in a desiccator for two months showed only $40 \%$ of the initial reducing activity.

\section{Application of the new reducing reagent to cyclohexanones 1a-e}

The results obtained with this new reagent for the reductive addition of deuterium to the substituted cyclohexanones 1a-e are summarized in Table 2. The reactions were carried out with $1.5 \mathrm{mmol}$ of lithium tri-sec-butylborodeuteride for $1 \mathrm{mmol}$ of ketone at $-80^{\circ} \mathrm{C}$ and were usually finished within 1-2 h. Yields were around 90\% after purification by chromatography, and the product contained $87 \%$ and more of the expected axial alcohols 2a-e. These values correspond well with results achieved with commercially available protic L-Selectride ${ }^{\circledR}$, ${ }^{4}$ which also gave the best selectivity for $\mathbf{1 d}$ and the least for $\mathbf{1 c}$. 
Table 2. Reduction of ketones 1a-e with in situ prepared lithium tri-sec-butylboro-deuteride solution

Substrate Reaction time [min] Overall yield [\%] Product ratio 2:3

\begin{tabular}{cccc}
\hline 1a & 120 & 92 & $89: 11$ \\
1b & 120 & 91 & $88: 12$ \\
1c & 120 & 87 & $87: 13$ \\
1d & 60 & 85 & $96: 4$ \\
1e & 90 & 95 & $97: 3$ \\
\hline
\end{tabular}

\section{Comparison of reduction procedures}

As already mentioned, most methods for the preparation of $\mathbf{2}$ involve the reduction of $\mathbf{1}$ to $\mathbf{3}$ followed by inversion at the carbinol carbon atom. In order to compare our reduction method with alternative routes of reducing cyclic ketones directly to equatorial alcohols a literature search revealed that reagents reported to give good stereoselectivity are $\mathrm{LiAlH}_{4} / \mathrm{AlCl}_{3}{ }^{7}$ and $\mathrm{NaBH}_{4} / \mathrm{CeCl}_{3}{ }^{8}{ }^{8}$ For a comparative study we selected the latter reagent because it is milder and easier to handle. Results of the reaction of $\mathrm{NaBD}_{4}$ added to as solution of ketones 1a-e and $\mathrm{CeCl}_{3} \cdot 7 \mathrm{H}_{2} \mathrm{O}$ (Method A) are summarized in Table 3 .

Table 3. Reduction of ketones 1a-e with $\mathrm{NaBD}_{4}$ in the presence of $\mathrm{CeCl}_{3}$ (Method A: To a methanol solution of ketone 1a-e and $\mathrm{CeCl}_{3}$ was added $\mathrm{NaBD}_{4}$ )

Substrate Reaction time [min] Overall yield [\%] Product ratio2:3 $\quad(2+3): 1$

\begin{tabular}{ccccc}
\hline 1a & 120 & $976:$ & 94 & - \\
1b & 1400 & 93 & $5: 95$ & $92: 8\left(\right.$ at $\left.60{ }^{\circ} \mathrm{C}\right)$ \\
1c & 20 & $7311:$ & $8964:$ & 36 \\
1d & 15 & $8339:$ & $61-$ & \\
1e & 15 & $9524:$ & $76-$ & \\
\hline
\end{tabular}

As expected, the observed stereoselectivity is in the same range as described for the nondeuterated compounds; ${ }^{8}$ the stereoselectivity values are better than those obtained with lithium tri-sec-butylborodeuteride for the 4-substituted cyclohexanones 1a,b and less favorable for the 2substituted ketones 1d,e. Overall yields are usually over $93 \%$ except for the volatile products 1c,d.

\section{Investigation of apparently incomplete reductions}

Surprisingly, in two cases (1b and 1c) the isolated reduction products contained some starting material. For the reduction of $\mathbf{1 b}$ the amount of unreacted starting material could be reduced to an acceptable degree by a prolonged reaction time and by raising the reaction temperature; in the 
case of the reduction of $1 c$ neither this measure nor the addition of more $\mathrm{NaBD}^{4}$ affected the result. Therefore, we investigated this reaction in more detail.

Table 4. Reduction of $1 \mathrm{c}$ in the presence of $\mathrm{CeCl}_{3}$ under various conditions (see text)

\begin{tabular}{cccccc}
\hline Method & $\begin{array}{c}\text { Reaction time } \\
{[\mathrm{min}]}\end{array}$ & $\begin{array}{c}\mathrm{CeCl}_{3} \\
\text { [equiv.] }\end{array}$ & $\begin{array}{c}\text { Overall yield } \\
{[\%]}\end{array}$ & $\begin{array}{c}\text { Product } \\
\text { ratio2c:3c }\end{array}$ & (2c+3c):1c \\
\hline A & 20 & 1 & 73 & $11: 8964:$ & 36 \\
A & 180 & 0.5 & 80 & $12: 8854:$ & 46 \\
B & 20 & 1 & 99 & $12: 88$ & 1c not detected \\
C & 20 & 1 & 99 & $10: 90$ & 1c not detected \\
\hline
\end{tabular}

Monitoring the reduction both of $\mathbf{1 b}$ and $\mathbf{1 c}$ with $\mathrm{NaBD}_{4} / \mathrm{CeCl}_{3}$ by TLC revealed that no starting material was left, but the formation of a new spot beside the reduction products was observed. This spot was absent after work-up with $2 \mathrm{~N}$ hydrochloric acid, but then the starting material was detected again. When the reduction was carried out without addition of $\mathrm{CeCl}_{3}$ the new spot did not appear. The amount of $\mathrm{CeCl}_{3}$ present in the methanol solution of $1 \mathrm{c}$ (Method A) affected neither conversion nor selectivity of the reduction (Table 4). The difference in yield and composition of the products may be attributed to the fact that $1 \mathrm{c}$ is very volatile, and in the first experiment more of 1c was lost during evaporation of the solvent. However, the absolute amount of 1c that was reduced can be calculated by multiplication of the yield of products $(\mathbf{1 c}+\mathbf{2 c}+3 \mathbf{c})$ with the content of $(2 c+3 c)$, and the results are nearly the same in the two reactions using method $\mathrm{A}(0.73 \times 0.64$ vs. $0.80 \times 0.54)$. These results suggest that $\mathrm{CeCl}_{3}$ catalyses the formation of the new product that was stable under the reaction conditions but was reverted into 1c upon work-up. When the reaction mixture was not acidified during work-up this reaction intermediate was isolated and proved to be the dimethyl ketal $\mathbf{4}$ (Figure 2). The ${ }^{1} \mathrm{H}$ NMR data of $\mathbf{4}$ correspond to those reported. ${ }^{9}$

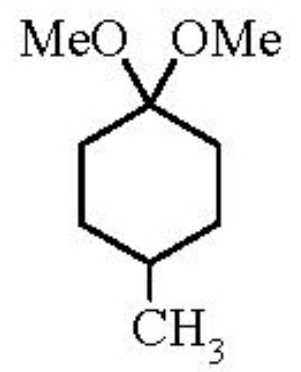

Figure 2

It is known that Ce(III)-exchanged montmorillonite efficiently catalyzes the formation of dimethylketals from ketones $(\mathbf{1 b}, \mathbf{1 c})$, but it was observed that some ketones react very slowly 
(1d) or not at all (1a). ${ }^{9}$ This is in good agreement with our results, i.e. only for $\mathbf{1 b}$ and $\mathbf{1 c}$ the reductive conversion was affected by the competing and faster ketal formation.

Although it was recently reported that $\left(\mathrm{NH}_{4}\right)_{2} \mathrm{Ce}\left(\mathrm{NO}_{3}\right)_{6}$ catalyzes ketone-ketal equilibration even under basic conditions ${ }^{10}$ we expected that in the presence of excess of basic $\mathrm{NaBD}_{4}$ no ketal formation would occur. To avoid premixing of $\mathbf{1 c}$ and $\mathrm{CeCl}_{3}$ substrate and reagents were added in different order: 1c was added to a mixture of $\mathrm{NaBD}_{4}$ and $\mathrm{CeCl}_{3}(\mathrm{Method}$ B); to 1c were added first $\mathrm{NaBD}_{4}$ and subsequently $\mathrm{CeCl}_{3}$ (Method C). Both Methods B and C did not afford compound $\mathbf{4}$ and yielded the reduction products $2 \mathrm{c}$ and $3 \mathrm{c}$ quantitatively, the diastereoselectivity is the same as achieved with Method A.

\section{Conclusions}

In summarizing, the reduction of substituted cyclohexanones 1a-e with the new sterically congested deuteride reagent lithium tri-sec-butylborodeuteride afforded predominantly axial 1$d_{1}$-cyclohexanols 2a-e, provided some crucial parameters were carefully observed. On the other hand, equatorial 1- $d_{1}$-cyclohexanols 3a-e were the major products resulting from the reduction with $\mathrm{NaBD}_{4} / \mathrm{CeCl}_{3}$. Notably, the comparison of the stereoselectivity of the reductions with $\mathrm{Li}(\text { sec-Bu })_{3} \mathrm{BD}$ and with $\mathrm{NaBD}_{4} / \mathrm{CeCl}_{3}$ converting ketones 1 into alcohols 2 (axial) and 3 (equatorial), respectively, reveals the following: The diastereoselectivity of the reduction of 2substituted cyclohexanones $\mathbf{1 d , e}$ with $\mathrm{Li}(\mathrm{sec}-\mathrm{Bu})_{3} \mathrm{BD}$ affording axial 1- $d_{1}$-cyclohexanols $2 \mathbf{d}, \mathbf{e}$ is significantly higher than that of the reduction of $\mathbf{1 d}$,e with $\mathrm{NaBD}_{4} / \mathrm{CeCl}_{3}$ yielding equatorial 1- $d_{1}$ cyclohexanols 3d,e. Inversely, the diastereoselectivity of the reduction of 4-substituted cyclohexanones 1a-c with $\mathrm{NaBD}_{4} / \mathrm{CeCl}_{3}$ furnishing equatorial 1- $d_{1}$-cyclohexanols 3a-c (Method A for 3a,b, Methods $\mathrm{B}$ and $\mathrm{C}$ for 3c) is slightly better than that of the reduction with Li(sec$\mathrm{Bu})_{3} \mathrm{BD}$ yielding axial $1-d_{1}$-cyclohexanols $2 \mathbf{2 a}-\mathbf{c}$. Thus, aiming at the stereoselective preparation of axial 1-d $d_{1}$-cyclohexanols 2a-c from 1a-c two synthetic routes may be considered: Direct reduction with $\mathrm{Li}(\mathrm{sec}-\mathrm{Bu})_{3} \mathrm{BD}$, and alternatively, reduction with $\mathrm{NaBD}_{4} / \mathrm{CeCl}_{3}$ followed by inversion of the resulting equatorial $1-d_{1}$-cyclohexanols 3a-c into the desired axial $1-d_{1}$ cyclohexanols 2a-c. Taking into account the additional reaction step of the latter route the reduction of cyclohexanones $\mathbf{1 a - c}$ like that of $\mathbf{1 d}, \mathbf{e}$ with $\mathrm{Li}(\mathrm{sec}-\mathrm{Bu})_{3} \mathrm{BD}$ affording axial $1-d_{1^{-}}$ cyclohexanols 2a-e appears to be the method of choice with regard to both chemical yield and diastereoselectivity.

\section{Experimental Section}

General Procedures. Melting points were determined using a Kofler apparatus. NMR spectra were recorded on a Bruker AC 200 spectrometer $\left(200 \mathrm{MHz}\right.$ ) using $\mathrm{CDCl}_{3}$ as solvent. Chemical shifts are recorded relative to $\mathrm{CHCl}_{3}\left(\delta_{\mathrm{H}} 7.24\right)$. GC/FID analyses of 
cyclohexanols were obtained with a Carlo Erba HRGC 5300 MEGA SERIES chromatograph equipped with an OV1 column $(10 \mathrm{~m}$; i.d. $0.53 \mathrm{~mm}$, room tmperature $3 \mu \mathrm{m}$ ) with a $4 \mathrm{~mL} / \mathrm{min}$ helium flow. Temperature program: Start temperature: $70{ }^{\circ} \mathrm{C} / /$ heating rate: $10{ }^{\circ} \mathrm{C} / \mathrm{min} / /$ end temperature $300{ }^{\circ} \mathrm{C}$. Signal assignment was based on retention times observed for commercially available perprotio-compounds. GC/MS analyses were conducted on a VOYAGER directly interfaced to a TRACE $2000 \mathrm{GC}$ gas chromatograph. $\left(70 \mathrm{eV}, 250^{\circ} \mathrm{C}\right)$. A DB-1 (17 m x $0.2 \mathrm{~mm}$ I.D., $0.11 \mu \mathrm{m}$ film thickness) crossbonded dimethyl polysiloxane capillary column (J \& W Scientific, Folsom, CA) was used in the split injection mode (10:1). The column head pressure of helium as carrier gas was set to $100 \mathrm{kPa}$. The oven temperature program was the same as for $\mathrm{GC} / \mathrm{FID}$ analyses. Injector and transfer line temperatures were set at $250{ }^{\circ} \mathrm{C}$ and $280{ }^{\circ} \mathrm{C}$. Chromatograms were recorded in scanning mode. The mass range was $\mathrm{m} / \mathrm{z} 40-400$ for 2a-e and 3a-e at a rate of $1.5 \mathrm{scans} / \mathrm{s}$. Data were processed with XCALIBUR software from Thermo Quest. All GC analyses were carried out with O-TMS-derivatives. ${ }^{11}$ Vacuum flash chromatography (VFC) was carried out with Merck silica gel 60 (230400 mesh). All reactions were monitored by TLC using Merck silica gel $60 \mathrm{~F}_{254}$ precoated aluminum plates; the chromatograms were visualized with ultraviolet light and were then developed with molybdato phosphoric acid (5\% in ethanol) and heating with a fan to visualize those spots, which cannot be detected with ultraviolet light. Dry organic solvents were prepared as follows: THF (sodium benzophenone ketyl), methanol (magnesium). Diethyl ether $\left(\mathrm{Et}_{2} \mathrm{O}\right)$, ethyl acetate (EtOAc), and petroleum ether (PE; bp 60-80) were distilled, all other solvents and reagents were used as purchased.

Reduction with lithium tri-sec-butylborodeuteride. Typical procedure. Methanol $(0.18 \mathrm{~mL}, 144 \mathrm{mg}, 4.5 \mathrm{mmol})$ was added to a solution of $\mathrm{LiAlD}_{4}(1.5 \mathrm{mmol})$ in THF (5 $\mathrm{mL}$ ) under an argon atmosphere and stirring, which was continued for 5 min prior to the addition of tri-sec-butylborane ( $1 \mathrm{M}$ in THF, $1.8 \mathrm{mmol}$ ). After stirring for further 15 min the reaction mixture was cooled to $-80{ }^{\circ} \mathrm{C}$, and a solution of 1a-e $(1 \mathrm{mmol})$ in THF $(2 \mathrm{~mL})$ was added slowly. The mixture was allowed to reach room temperature within 2 $\mathrm{h}$ and was quenched with water $(2 \mathrm{~mL})$ and $2 \mathrm{~N}$ hydrochloric acid $(7 \mathrm{~mL})$. The aqueous layer was saturated with sodium chloride, the organic phase was separated, and the aqueous phase was extracted twice with diethyl ether. The combined organic extracts were dried with $\mathrm{MgSO}_{4}$, and the solvent was evaporated. The residual oil was purified by VFC (PE:Et ${ }_{2} \mathrm{O}, 100: 1$ to 1:1) to give 2a-e (cf. Table 2). The diastereomers were not separated.

cis-1-Deutero-4-phenylcyclohexanol (2a). Colorless crystals $(78 \% \mathrm{de}) ; \mathrm{R}_{f}=0.43$ (PE/EtOAc 2:1); mp 72-74 ${ }^{\circ} \mathrm{C}(\mathrm{PE}) ;{ }^{1} \mathrm{H}$ NMR $\left(200 \mathrm{MHz}, \mathrm{CDCl}_{3}\right): \delta 1.55-1.78(\mathrm{~m}, 4 \mathrm{H}$, $\left.3,5-\mathrm{H}_{\mathrm{ax}}, 3,5-\mathrm{H}_{\mathrm{eq}}\right), 1.79-2.1\left(\mathrm{~m}, 4 \mathrm{H}, 2,6-\mathrm{H}_{\mathrm{ax}}, 2,6-\mathrm{H}_{\mathrm{eq}}\right), 2.45-2.70\left(\mathrm{~m}, 1 \mathrm{H}, 4-\mathrm{H}_{\mathrm{ax}}\right), 7.1-7.4$ (m, 5H, $\mathrm{H}_{\text {phenyl }}$ ); MS: m/z 249 (O-TMS derivative). 
cis-1-Deutero-4-(1,1-dimethylethyl)cyclohexanol (2b). ${ }^{12}$ Colorless crystals $(76 \% \mathrm{de})$; $\mathrm{R}_{f}=0.68$ (PE:EtOAc 2:1); mp 70-72 ${ }^{\circ} \mathrm{C}$ (PE) (lit. ${ }^{12 \mathrm{a}} \mathrm{mp} 78-78.5{ }^{\circ} \mathrm{C}$; lit. ${ }^{12 \mathrm{~b}} \mathrm{mp} 80{ }^{\circ} \mathrm{C}$ ); ${ }^{1} \mathrm{H}$ NMR $\left(200 \mathrm{MHz}, \mathrm{CDCl}_{3}\right): \delta 1.85\left(\mathrm{~s}, 9 \mathrm{H}, 3 \mathrm{CH}_{3}\right), 1.1-1.3\left(\mathrm{~m}, 5 \mathrm{H}, 3,5-\mathrm{H}_{\mathrm{ax}}, 3,5-\mathrm{H}_{\mathrm{eq}}, 4-\right.$ $\mathrm{H}_{\mathrm{ax}}$ ), 1.31-1.6 (m, 4H, 2,6- $\mathrm{H}_{\mathrm{ax}}, 2,6-\mathrm{H}_{\mathrm{eq}}$ ); MS: m/z 229 (O-TMS derivative).

cis-1-Deutero-4-methylcyclohexanol (2c). Colorless oil $\left(\begin{array}{lll}74 \% & \mathrm{de}\end{array}\right) ; \quad \mathrm{R}_{f}=0.55$ (PE:EtOAc 2:1); ${ }^{1} \mathrm{H}$ NMR (200 MHz, $\left.\mathrm{CDCl}_{3}\right): \delta 0.99$ (d, 3H, $\left.\mathrm{CH}_{3}\right), 1.2-1.8(\mathrm{~m}, 9 \mathrm{H}, 3,5-$ $\left.\mathrm{H}_{\mathrm{ax}}, 3,5-\mathrm{H}_{\mathrm{eq}}, 2,6-\mathrm{H}_{\mathrm{ax}}, 2,6-\mathrm{H}_{\mathrm{eq}}, 4-\mathrm{H}_{\mathrm{ax}}\right)$; MS: $\mathrm{m} / \mathrm{z} 187$ (O-TMS derivative).

cis-1-Deutero-2-methylcyclohexanol $(2 d){ }^{13}$ Colorless $\quad$ oil $(92 \%$ de $) ; \quad \mathrm{R}_{f}=0.69$ (PE:EtOAc 2:1); lit. $^{13}$ reports no data of this product; ${ }^{1} \mathrm{H}$ NMR $\left(200 \mathrm{MHz}, \mathrm{CDCl}_{3}\right): \delta$ $0.92\left(\mathrm{~d}, 3 \mathrm{H}, \mathrm{CH}_{3}\right), 1.2-1.8\left(\mathrm{~m}, 9 \mathrm{H}, 2,3,4,5,6-\mathrm{H}_{\mathrm{ax}}, 3,4,5,6-\mathrm{H}_{\mathrm{eq}}\right) ; \mathrm{MS}: \mathrm{m} / \mathrm{z} 187$ (O-TMS derivative).

(1S)-1 $\alpha$-Deutero-5 $\beta$-methyl-2 $\alpha$-(1-methylethyl)cyclohexanol

(1-Deutero-(+)neomenthol) (2e). Colorless oil (94\% de); $\mathrm{R}_{f}=0.41$ (PE:EtOAc 8:1); ${ }^{1} \mathrm{H}$ NMR (200 $\left.\mathrm{MHz}, \mathrm{CDCl}_{3}\right): \delta 0.7-1.89\left(\mathrm{~m}, 18 \mathrm{H}, 5-\mathrm{CH}_{3}, \mathrm{CH}\left(\mathrm{CH}_{3}\right)_{2}, 2,3,4,5,6-\mathrm{H}_{\mathrm{ax}}, 3,4,6-\mathrm{H}_{\mathrm{eq}}\right) . \mathrm{MS}$ : $\mathrm{m} / \mathrm{z} 229$ (O-TMS derivative).

Reduction with $\mathrm{NaBD}_{4} / \mathrm{CeCl}_{3}$. Typical procedures with different modes of mixing the reagents

Method A. To a solution of 1a-e $(1.0 \mathrm{mmol})$ and $\mathrm{CeCl}_{3} \cdot 7 \mathrm{H}_{2} 0(0.33 \mathrm{~g}, 1.0 \mathrm{mmol})$ in methanol $(3 \mathrm{~mL})$ was added $\mathrm{NaBD}_{4}(42 \mathrm{mg}, 1.0 \mathrm{mmol})$ in one portion.

Method B. To a solution of $\mathrm{CeCl}_{3} \cdot 7 \mathrm{H}_{2} 0(0.33 \mathrm{~g}, 1.0 \mathrm{mmol})$ in methanol $(3 \mathrm{~mL})$ were rapidly added $\mathrm{NaBD}_{4}(42 \mathrm{mg}, 1.0 \mathrm{mmol})$, and subsequently, a solution of $1 \mathrm{c}(1.0 \mathrm{mmol})$ in methanol $(2 \mathrm{~mL})$.

Method C. To a solution of 1c $(1.0 \mathrm{mmol})$ in methanol $(5 \mathrm{~mL})$ were rapidly added $\mathrm{NaBD}_{4}(42 \mathrm{mg}, 1.0 \mathrm{mmol})$, and subsequently, $\mathrm{CeCl}_{3} \cdot 7 \mathrm{H}_{2} 0(0.33 \mathrm{~g}, 1.0 \mathrm{mmol})$. In all caes a vigorous gas evolution occurred, and the temperature rose to $40^{\circ} \mathrm{C}$. The mixture was stirred for some time (see Tables 3,4$)$ before quenching with water $(2 \mathrm{~mL}$ ) and $2 \mathrm{~N}$ hydrochloric acid $(7 \mathrm{~mL})$. Methanol was evaporated, and the residual solution was saturated with sodium chloride and extracted twice with $\mathrm{Et}_{2} \mathrm{O}$. The combined organic extracts were washed with a saturated $\mathrm{NaHCO}_{3}$ solution and dried with $\mathrm{MgSO}_{4}$ to yield 3a-e after evaporation of the solvent (cf. Table 3; Table 4 for 3c). The diastereomers were not separated.

trans-1-Deutero-4-phenylcyclohexanol (3a). ${ }^{14}$ Colorless crystals (Method A; 88\% de); $\mathrm{R}_{f}=0.27$ (PE:EtOAc 2:1); mp $118-120{ }^{\circ} \mathrm{C}$ (PE) (lit. ${ }^{14} \mathrm{mp} 118-119{ }^{\circ} \mathrm{C}$ );.${ }^{1} \mathrm{H}$ NMR $(200$ $\left.\mathrm{MHz}, \mathrm{CDCl}_{3}\right): \delta 1.4-1.8\left(\mathrm{~m}, 4 \mathrm{H}, 3,5-\mathrm{H}_{\mathrm{ax}}, 3,5-\mathrm{H}_{\mathrm{eq}}\right), 1.8-2.2\left(\mathrm{~m}, 4 \mathrm{H}, 2,6-\mathrm{H}_{\mathrm{ax}}, 2,6-\mathrm{H}_{\mathrm{eq}}\right)$, 2.4-2.6 (m, 1H, 4- $\left.\mathrm{H}_{\mathrm{ax}}\right), 7.12-7.4$ ( $\mathrm{m}, 5 \mathrm{H}, \mathrm{H}_{\text {phenyl }}$ ); MS: m/z 249 (O-TMS derivative).

trans-1-Deutero-4-(1,1-dimethylethyl)cyclohexanol (3b). ${ }^{12}$ Colorless crystals (Method A; the product contained $8 \%$ of $\mathbf{1 b} ; 90 \% \mathrm{de}$ ); $\mathrm{R}_{f}=0.40$ (PE:EtOAc $2: 1$ ); mp $73-74.5^{\circ} \mathrm{C}$ (PE) (lit. ${ }^{12 \mathrm{a}} \mathrm{mp} 76-77{ }^{\circ} \mathrm{C}$; lit. $\left.{ }^{12 \mathrm{~b}} \mathrm{mp} 76{ }^{\circ} \mathrm{C}\right) ;{ }^{1} \mathrm{H}$ NMR $\left(200 \mathrm{MHz}, \mathrm{CDCl}_{3}\right): \delta 0.85(\mathrm{~s}, 9 \mathrm{H}$, $\left.3 \mathrm{CH}_{3}\right), 0.9-1.3\left(\mathrm{~m}, 4 \mathrm{H}, 3,5-\mathrm{H}_{\mathrm{ax}}, 3,5-\mathrm{H}_{\mathrm{eq}}\right), 1.32-1.52\left(\mathrm{~m}, 1 \mathrm{H}, 4-\mathrm{H}_{\mathrm{ax}}\right), 1.6-2.08(\mathrm{~m}, 4 \mathrm{H}$, 
2,6- $\left.\mathrm{H}_{\mathrm{ax}}, 2,6-\mathrm{H}_{\mathrm{eq}}\right)$; MS: m/z 229 (O-TMS derivative).

trans-1-Deutero-4-methylcyclohexanol (3c). Colorless oil (Method C; 80\% de); $\mathrm{R}_{f}=$ 0.40 (PE:EtOAc 2:1); ${ }^{1} \mathrm{H}$ NMR $\left(200 \mathrm{MHz}, \mathrm{CDCl}_{3}\right): \delta 0.9\left(\mathrm{~d}, 3 \mathrm{H}, \mathrm{CH}_{3}\right), 0.9-2.1(\mathrm{~m}, 9 \mathrm{H}$, 3,5- $\mathrm{H}_{\mathrm{ax}}, 3,5-\mathrm{H}_{\mathrm{eq}}, 2,6-\mathrm{H}_{\mathrm{ax}}, 2,6-\mathrm{H}_{\mathrm{eq}}, 4-\mathrm{H}_{\mathrm{ax}}$ ); MS: m/z 187 (O-TMS derivative).

trans-1-Deutero-2-methylcyclohexanol (3d). ${ }^{13}$ Colorless oil (Method A; 22\% de); $\mathrm{R}_{f}=$ 0.59 (PE:EtOAc 2:1); lit. ${ }^{13}$ reports no data of this product. ${ }^{1} \mathrm{H}$ NMR $\left(200 \mathrm{MHz}, \mathrm{CDCl}_{3}\right)$ : $\delta 1.0\left(\mathrm{~d}, 3 \mathrm{H}, \mathrm{CH}_{3}\right), 1.1-2.1\left(\mathrm{~m}, 9 \mathrm{H}, 2,3,4,5,6-\mathrm{H}_{\mathrm{ax}}, 3,4,5,6-\mathrm{H}_{\mathrm{eq}}\right)$; MS: m/z $187(O-\mathrm{TMS}$ derivative).

(1R)-1 $\alpha$-Deutero-5 $\alpha$-methyl-2 $\beta$-(1-methylethyl)cyclohexanol

[1-Deutero-(-)menthol] (3e). Colorless oil, partially forming crystals on standing (Method A; 52\% de); $\mathrm{R}_{f}=0.52$ (PE:EtOAc 8:1); ${ }^{1} \mathrm{H}$ NMR $\left(200 \mathrm{MHz}, \mathrm{CDCl}_{3}\right): \delta 0.75-2.29(\mathrm{~m}, 18 \mathrm{H}, 5-$ $\left.\mathrm{CH}_{3}, \mathrm{CH}\left(\mathrm{CH}_{3}\right)_{2}, 2,3,4,5,6-\mathrm{H}_{\mathrm{ax}}, 3,4,6-\mathrm{H}_{\mathrm{eq}}\right)$; MS: m/z 229 (O-TMS derivative).

\section{References}

1. Geyer, H.; Schänzer, W.; Mareck-Engelke, U.; Nolteernsting, E.; Opfermann, G. In Recent Advances in Doping Analysis, Proceedings of the Manfred Donike Workshop, $15^{\text {th }}$ Cologne Workshop on Dope Analysis, Schänzer, W.; Geyer, H.; Gotzmann, A.; Mareck-Engelke, U. Eds.; Sport und Buch Strauss: Köln, 1997; p 99.

2. (a) Davis, A. P. In Houben-Weyl, $4^{\text {th }}$ Edn, Vol. E21d. (b) Helmchen, G.; Hoffmann, R. W.; Mulzer, J.; Schaumann, E. Ed.; Thieme: Stuttgart, 1995; p 4026.

3. (a) Radüchel, B. Synthesis 1980, 292. (b) Mitsunobu, O. Synthesis 1981, 1. (c) Martin, S. F.; Dodge, J. A. Tetrahedron Lett 1991, 32, 3017.

4. (a) Brown, H. C; Krishnamurthy, S. J. Am. Chem. Soc. 1972, 94, 7159. (b) Brown, H. C.; Krishnamurthy, S.; Hubbard, J. L. J. Organomet. Chem. 1979, 166, 271.

5. Brown, H. C.; Hubbard, J. L.; Singaram, B. Tetrahedron 1981, 37, 2359.

6. Brown, H. C.; Singaram, B. Inorg. Chem. 1980, 19, 455.

7. Eliel, E. L.; Rerick, M. N. J. Am. Chem. Soc. 1960, 82, 1367.

8. Gemal, A. L.; Luche, J.-L. J. Am. Chem. Soc. 1981, 103, 5454.

9. Tateiwa, J.; Horiuchi, H.; Uemura, S. J. Org. Chem. 1995, 60, 4039.

10. Markó, I. E.; Ates, A.; Gautier, A.; Leroy, B.; Plancher, J.-M.; Quesnel, Y.; Vanherck, J.-C. Angew. Chem. 1999, 111, 3411; Angew. Chem. Int. Ed. 1999, 38, 3207.

11. Donike, M.; Zimmermann, J. J. Chromatogr. 1980, 202, 483.

12. (a) Banks, R. M.; Maskill, H.; Natarajan, R.; Wilson, A. A. J. Chem. Soc., Perkin Trans. 2 1980, 427. (b) Pétrier, C.; Lavaitte, S.; Morat, C. J. Org. Chem. 1990, 55, 1664.

13. Briggs, W. S.; Djerassi, C. J. Org. Chem. 1968, 33, 1612.

14. Corey, E. J.; Howell, M. G.; Boston, A.; Young, R. L.; Sneen, R. A. J. Am. Chem. 
Soc. 1956, 78, 5036. 